\title{
Simple Indicators of Energy Malnutrition in Patients With Chronic Liver Diseases
}

Hitomi Takada ( $\square$ takadahi0107@gmail.com)

First Department of Internal Medicine Faculty of Medicine, University of Yamanashi 1110 Shimokato, Chuo-city, Yamanashi, 409-3898, Japan https://orcid.org/0000-0003-2101-0454

\section{Fumitake Amemiya}

Municipal Hospital of Kofu

Tomoki Yasumura

Municipal Hospital of Kofu

Hiroki Yoda

Municipal Hospital of Kofu

Tetsuya Okuwaki

Municipal Hospital of Kofu

Keisuke Tanaka

Municipal Hospital of Kofu

Makoto Kadokura

Municipal Hospital of Kofu

\section{Nobuyuki Enomoto}

University of Yamanashi: Yamanashi Daigaku

\section{Research}

Keywords: Energy malnutrition, Free fatty acid, \% Arm circumference

Posted Date: October 6th, 2020

DOI: https://doi.org/10.21203/rs.3.rs-77469/v1

License: (c) (i) This work is licensed under a Creative Commons Attribution 4.0 International License. Read Full License 


\section{Abstract}

Objective: Protein-energy malnutrition (PEM) is an important prognostic factor in patients with cirrhosis. Energy malnutrition (EM) is defined by the Japanese Society of Gastroenterology Guidelines for cirrhosis as a non-protein respiratory quotient $<0.85$, a $\%$ arm circumference $(\% A C)<95 \%$, or a free fatty acid (FFA) value $>660 \mu E q / L$. The parameters associated with EM are difficult to measure in all patients. In this study, we evaluated simple indicators of EM.

Methods: This retrospective study included 295 patients with chronic liver diseases (CLDs) in whom serum FFA values or \%AC were measured at the Department of Gastroenterology at the Municipal Hospital of Kofu. We examined the characteristics of the patients with EM.

Results: EM was observed in $36 \%$ of patients with CLDs without a late-evening snack (LES). The frequency of EM was high in patients with Child-Pugh grade B or C, $Y$-GTP level $\geq 100 \mathrm{U} / \mathrm{ml}$, AST level $\geq 27 \mathrm{IU} / \mathrm{l}$, and ALT level $\geq 27 \mathrm{IU} / \mathrm{I}$ in males, and Child-Pugh grade B or C, $y-G T P \geq 84 \mathrm{U} / \mathrm{ml}, A S T \geq 24 \mathrm{IU} / \mathrm{I}$, and ALT $\geq 28 \mathrm{IU} / \mathrm{I}$ in females. Among the three indicators of Child-Pugh grade B or C, increased $\mathrm{Y}$-GTP levels, and increased transaminase values, EM was observed in $16 \%, 35 \%, 59 \%$, and $57 \%$ of patients who were positive for $0,1,2$, or 3 of the indicators. The frequency of EM in patients with Child-Pugh grade A was high for increased $y$-GTP, AST, and ALT levels. Among the two indicators of increased $y$-GTP, and transaminase levels, $16 \%, 32 \%$, and $67 \%$ of patients were positive for 0,1 , or 2 of the indicators.

Conclusion: Child-Pugh grade, transaminase values, and y-GTP levels were useful indicators of EM in patients with CLDs. We should evaluate positively the presence of EM in cases with poor liver function, high transaminase concentrations, or high $\mathrm{y}$-GTP levels.

\section{Background}

Protein-energy malnutrition (PEM) is a prognostic factor in patients with cirrhosis. Protein malnutrition (PM) is defined by the Japanese Society of Gastroenterology Guidelines for cirrhosis as a serum albumin value $\leq 3.5 \mathrm{~g} / \mathrm{dl}$, and energy malnutrition (EM) as a non-protein respiratory quotient (npRQ) $<0.85$, a \% arm circumference $(\% A C)<95 \%$, or a free fatty acid (FFA) value $>660 \mu \mathrm{Eq} / \mathrm{L}$, for which therapeutic interventions are recommended[1]. Shiraki et al. used the $n p R Q$ from 294 cases with cirrhosis, including 154 Child-Pugh A cases, and reported that $43 \%$ of them had EM, 61\% had PM, and $27 \%$ had PEM $[2,3]$. Tajika et al. used the npRQ to report that $62 \%$ of patients with cirrhosis had EM, $70 \%$ had PM, and $50 \%$ had PEM [4]. Carvalho et al. examined \%AC, \% arm muscle circumference, and serum albumin values, using the formula reported by Medenhall et al. for the diagnosis of malnutrition, and found that $21 \%, 52 \%$ and $58 \%$ of Child-Pugh $A, B$, and $C$ patients with cirrhosis had PEM, respectively $[5,6]$.

However, the parameters that are normally used to diagnose EM, including npRQ, \%AC, and FFA, are difficult to measure in all patients in clinical practice. In this study, we examined the usual indicators of EM and analyzed the characteristics of patients with chronic liver disease in an effort to find simple indicators of EM.

\section{Methods}

Patients

From April 2019 to February 2020, we studied 295 patients with chronic liver diseases (CLDs) in whom serum FFA values or \%AC were measured and analyzed retrospectively at the Department of Gastroenterology at the Municipal Hospital of Kofu. All patients participating in this study provided informed consent, and the study was conducted according to the 
Helsinki Declaration and approved by the Ethics Committee for Clinical Studies of the Municipal Hospital of Kofu (Rinshoukenkyu-Rrinrishinsa-linkai (in Japanese), approval number 31-8).

Evaluation of serum FFA

Serum FFA values were measured in venous blood collected between 7 and 10 AM after fasting overnight from 8 PM the previous night for $10-14 \mathrm{~h}$. After collection, blood was refrigerated at $4^{\circ} \mathrm{C}$ and prompt testing was conducted within $24 \mathrm{~h}$ using an enzymatic assay [7]. EM was defined as a serum FFA value $>660 \mu \mathrm{Eq} / \mathrm{L}$ in this study [1-4]

Evaluation of \%AC

We measured the arm of the non-paralyzed side and non-dominant arm using the insert-tape and adipometer from the Japanese anthropometry reference data (JARD) 2001. AC was measured at the midpoint of the height between the acromion process and the olecranon process. Three measurements were taken and the mean value was used. JARD2001 provided data on body measurements of 5,492 healthy subjects adjusted for gender and age; moreover, for percent notation, the median was calculated as $100 \%[8,9]$. EM was defined as a \%AC $<95 \%$ in this study [1-4].

Statistical analysis

Values are shown as the median and range. Fisher's test was used for categorical variables. The Kolmogorov-Smirnov test was used to evaluate normality. Student's t-test was used for continuous variables. The best cut-off values in the receiver operating characteristic (ROC) analysis were determined by the Youden index. Significance was at $P<0.05$. All statistical analyses were performed using EZR (Saitama Medical Center, Jichi Medical University, Saitama, Japan), which is a graphical user interface for R (The R Foundation for Statistical Computing, Vienna, Austria); more specifically, it is a modified version of the $\mathrm{R}$ commander designed to include statistical functions that are frequently used in biostatistics[10].

\section{Results}

Baseline characteristics of the study subjects

The characteristics of the study subjects $(n=295)$ are shown in Table 1 and Figure 1 . The median age of the patients was 72 (range, 20-94) years, with 172 males (58\%). One hundred patients (34\%) had chronic hepatitis, while 195 patients $(66 \%)$ had liver cirrhosis. One hundred and one patients $(34 \%)$ reported a history of therapy for hepatocellular carcinoma. Patients with EM had a significantly shorter survival than did patients without EM $(P<0.001)$ (Figure 2). Nineteen cases have used a late-evening snack (LES). LES has been reported to decrease FFA, and only 276 cases without LES were included in the follow study [11].

\section{Baseline characteristics of patients without a LES}

The median age of patients without a LES $(n=276)$ was $72(20-94)$ years, and the cohort included 158 males $(57 \%)$. We found 100 cases $(36 \%)$ of chronic hepatitis and 176 cases $(64 \%)$ of liver cirrhosis, whereas the number of cases of hepatitis B virus, hepatitis $C$ virus, alcohol, nonalcoholic steatohepatitis, and other conditions was $37,130,35,53$, and 21 , respectively. Two hundred and eighteen, 49, and 9 patients were Child-Pugh A, B, and C grade. Regarding comorbid diseases, we identified 76 cases of diabetes, 33 of chronic heart disease, 19 of chronic lung disease, 26 of cerebrovascular disease, and 26 of chronic renal failure. EM was observed in 98 cases (36\%).

Risk factors for EM in patients with CLDs without a LES

Page 3/16 
Table 2 shows the characteristics of patients without a LES who were grouped as having or not having EM. The frequency of EM was significantly higher in patients with Child-Pugh grade B or C (OR 2.8, $P<0.001)$, low body mass index (BMI) (OR 1.1, $P=0.001)$, increased gamma glutamyltransferase $(\gamma-G T P)$ levels (OR 1.01, $P<0.001)$, increased aspartate aminotransferase (AST) levels (OR 1.02, $P<0.001)$, and increased alanine aminotransferase (ALT) levels (OR $1.02, P<0.001)$ (Table 3$)$. Using the cut-off values calculated from the ROC curves, in males $(\mathrm{n}=158)$, Child-Pugh grade B or C (OR 2.9, $P<0.001)$, BMl<22 (OR 2.1, $P=0.031)$, Y-GTP $\geq 100 \mathrm{U} / \mathrm{ml}($ OR 6.5, $P<0.001)$, AST $\geq 27$ IU/I (OR 3.3, $P<$ $0.001), A L T \geq 27$ IU/I (OR 2.4, $P=0.016)$; and in females $(n=118)$, Child-Pugh grade $B$ or $C$ (odds ratio 2.8, $P=0.031), Y^{-}$ $\mathrm{GTP} \geq 84 \mathrm{U} / \mathrm{ml}(\mathrm{OR} 3.4, P=0.020)$, AST $\geq 24 \mathrm{IU} / \mathrm{I}(\mathrm{OR} 3.2, P=0.013), \mathrm{ALT} \geq 28 \mathrm{IU} / \mathrm{I}(\mathrm{OR} 3.4, P=0.0028)$ values were risk factors for EM (Table 4). Among the three common items of Child-Pugh grade B or C, increased Y-GTP levels, and increased transaminase levels, EM was observed in $16 \%, 35 \%, 59 \%$, and $57 \%$ of patients who were positive for $0,1,2$, or 3 of the items, respectively (Figure 3).

Risk factors for EM in patients without LES classified as Child-Pugh grade A

In Child-Pugh grade A patients without a LES $(n=218)$, the frequency of EM was high among patients with increased $\gamma^{-}$ GTP (males $\geq 100$, females $\geq 84 \mathrm{U} / \mathrm{ml}$ ) (OR 6.7, $P<0.001$ ), increased AST (males $\geq 27$, females $\geq 24$ IU/I) $($ OR $3.4, P<$ 0.001 ), and increased ALT (males $\geq 27$, females $\geq 28$ IU/I) (OR 2.7, $P<0.001$ ) levels. High $Y$-GTP and high transaminase values were independent factors for predicting the presence of EM in patients with Child-Pugh grade $A$ (Table 5).Among the two items of increased Y-GTP and increased AST or ALT levels, $16 \%, 32 \%$, and $67 \%$ of cases were positive for 0,1 , or 2 of the items, respectively (Figure 4).

\section{Discussion}

PEM is a poor prognosis factor in chronic liver disease $[1,2,11,12]$ and has been associated with abdominal fluid retention, hepatic encephalopathy, rupture of esophageal gastric varicose veins, hepato-renal syndrome, sarcopenia, and decreased quality of life (QOL) $[2,13,14]$. In Japan, according to the treatment guidelines for liver cirrhosis of the Japanese Gastroenterological Society, EM is defined as a $\mathrm{npRQ}<0.85, \% \mathrm{AC}<95 \%$, or FFA $>660 \mu \mathrm{Eq} / \mathrm{L}$ [1]. However, compared with PM, which is diagnosable based on albumin values alone, it is difficult to measure the parameters that are used to diagnose EM in all patients. Therefore, EM is often underdiagnosed, particularly in early-stage CLDs such as chronic hepatitis and Child-Pugh A cirrhosis. In this study, we focused on EM and examined the simple items that are easy to use in daily clinical care as indicators of EM.

Measurement of the npRQ using indirect calorimetry is an established method for the diagnosis of EM[15]. In patients with cirrhosis, EM is associated with a decrease in glycogen storage caused by increased energy consumption at rest and liver atrophy. The sugar ratio, which is an energy source during early morning fasting, decreases and the lipid ratio increases. As a result, EM occurs [16]. Increased insulin resistance and increased blood concentrations of glucagon, catecholamines, and cortisol are also involved in reducing the utilization efficiency of carbohydrates as an energy substrate. A previous study using the $n p R Q$ revealed that age $>64$ years, AST $>40 \mathrm{IU} / \mathrm{L}$, branched-chain amino acid to tyrosine ratio $\leq 5.2$, and increased serum hyaluronic acid levels were associated with PEM[3, 17]. However, npRQ measurement is costly and can only be carried out in a limited number of facilities. Therefore, a simple substitute marker for the diagnosis of EM is required, and \%AC and FFA have been reported to be useful correlates of npRQ measurement $[18,19]$. In this study, we used \%AC or FFA to diagnose EM, as we were not able to measure npRQ at our facility.

$\% A C$ is a method that is used for evaluating muscle mass based of body measurements and is employed as a parameter of nutritional assessment. \%AC is correlated with the skeletal muscle mass measurements of the whole body in the elderly, as obtained from dual-energy X-ray absorptiometry [9]. A decrease in AC is a poor prognosis factor for healthy 
elderly people, and a decrease in AC over time is associated with a deterioration of the activities of daily living in the elderly Japanese people [20]. The survival of patients whose AC was in the 10th or lower percentile was significantly shorter $[18,21]$. Although the measurement error is minimized by the standardization of the methods of measurement, the measurer must be an expert who is familiar with the procedure. The measurement error is large in cases involving thick subcutaneous fat [9]; moreover, we should consider the measurement errors resulting from fluid retention in patients with decompensated cirrhosis [22, 23].

FFA accounts for approximately $5 \%$ of total lipids, and its blood concentrations are regulated by uptake into the liver through the action of the hormone-sensitive lipase and lipoprotein lipase (LPL) enzymes [24]. Plasma levels of FFA were correlated with npRQ $(r=-0.39, P<0.001)$, and the FFA value that predicted a npRQ of 0.85 was $660 \mu \mathrm{Eq} / \mathrm{L}$. In patients with cirrhosis, decreased liver processing of FFA and increased LPL activity result in increased FFA levels [25, 26]. FFA is associated with hepatic encephalopathy and the onset of dementia in patients with cirrhosis [19, 24, 27-30]. FFA decreases with dietary intake, exercise, and use of hypoglycemic agents, but it increases with fasting, smoking, aging, growth hormone, and catecholamines [31]. Therefore, it is necessary to consider the patient's background when diagnosing EM based on FFA.

In this study, we report for the first time that Child-Pugh grade and increased levels of $\mathrm{Y}$-GTP, AST, and ALT may suggest EM in patients with CLDs. Our facility cannot measure npRQ and FFA using the in-house testing system, and we believe this report is useful for the simple enclosurement of patients with EM. In patients with CLDs, Child-Pugh grade B or C, and high levels of $\mathrm{Y}$-GTP, AST, or ALT were risk factors for EM, and patients who were positive for $0,1,2$, or 3 of the items developed EM in $16 \%, 35 \%, 59 \%$, and $57 \%$ of cases, respectively. In patients with Child-Pugh grade $A$ in whom the levels of $\mathrm{Y}$-ATP, AST, or ALT were measured, those positive for 0,1 , or 2 of the items developed EM in $16 \%, 32 \%$, and $67 \%$ of cases, respectively.

The blood concentration of cytokines is reported to be significantly higher in patients with cirrhosis than in non-cirrhosis patients because of abnormal intestinal flora, bacterial translocation resulting from portal hypertension, and a decrease in reticuloendothelial function [32,33]. The secretion of cytokines is mainly due to the infiltration of lymphocytes into the liver as a result of inflammation and liver damage. In particular, the tumor necrosis factor-a (TNF-a), interleukin (IL)-1, or IL-6, inhibits glucose oxidation, thus affecting fat combustion, and is associated with EM in patients with cirrhosis [32, 34-39]. In cases of inflammation and liver damage showing high values of $y$-GTP and transaminases, blood cytokine levels are expected to increase, and the frequency of EM expected to increase.

For the treatment of malnutrition in patients with cirrhosis, guidelines such as ESPEN and ASPEN have been proposed [1, $11,40]$. Patients with EM showed increased AC and reduced FFA after 1 month of diet management [41]. After the administration a LES to patients with EM, a decrease in FFA and an improvement in QOL were observed [14, 41-43]. In this study, FFA values were significantly higher in cases without a LES compared with those with a LES (453 \pm 307 vs. $278 \pm 359 \mu \mathrm{Eq} / \mathrm{L}, P=0.031$ ) (Figure 5). Further research is needed regarding the relationship between changes in FFA, $\% \mathrm{AC}$, treatment intervention, and prognosis.

This study had some limitations. It was conducted at a single facility and included a small number of cases, with few cases of Child-Pugh grade B or C. Furthermore, the relationship between ethiology, physical activity, and EM could not be investigated. Among the 43 cases in which both FFA and \%AC were measured, there were 19 cases in which the results regarding the judgement of EM based on FFA and \%AC differed. Three cases had $\% A C \geq 95 \%$ and FFA $>660 \mu E q / L$, and all of whom were female and were diagnosed with myopenia based on CT imaging. Conversely, the remaining 16 cases had $\% A C<95 \%$ and FFA $\leq 660,13$ of whom were male. The diagnosis of EM based on \%AC alone in women or FFA alone in men can be difficult, and measurements of both \%AC and FFA should be performed whenever possible. In addition, EM cases tended to have radiological attenuation of iliopsoas muscle, low subcutaneous fat mass index (SFMI), and low visceral fat mass index (VFMI) in this study. The radiological attenuation of iliopsoas muscle, SFMI, and VFMI are 
findings suggesting low BMI, muscle atrophy, and fat infiltration. Detailed studies by sex including imaging should be conducted in the future.

In clinical practice, it is difficult to measure npRQ, \%AC, and FFA in all cases of CLDs. This is the first report to predict EM using low-cost, and simple standardized test items, such as Y-GTP, AST, and ALT levels. Nevertheless, it will be necessary to accumulate additional case data for further analysis.

\section{Conclusion}

The predictive factors of EM in patients with CLDs were Child-Pugh grade, transaminase values, and $Y$-GTP values. This information may help select cases to be actively evaluated for the presence of EM using accurate diagnostic methods, such as npRQ, \%AC, and FFA.

\section{Declarations}

Ethical Approval and Consent to participate

This study was approved by the Ethics Committee for Clinical Studies of the Municipal Hospital of Kofu (RinshoukenkyuRrinrishinsa-linkai (in Japanese), approval number 31-8). All of the protocols and procedures were performed according to the Declaration of Helsinki.

Consent for publication

Not applicable.

Availability of supporting data

The datasets during the current study available from the corresponding author on reasonable request. Acknowledgements

There are no funders to report for this submission.

Authors' contributions.

study concept and design; H.T

acquisition of data; H.T, F.A, Y.T, H.Y, T.O, K.T, M.K

analysis and interpretation of data; H.T

drafting of the manuscript; H.T

critical revision; F.A, M.K, N.E

study supervision; F.A, M.K, N.E

All authors reviewed and approved final version of the manuscript.

Competing interests

Hitomi Takada, Fumitake Amemiya, Tomoki Yasumura, Hiroki Yoda, Tetsuya Okuwaki , Keisuke Tanaka, Makoto Kadokura, and Nobuyuki Enomoto declare that they have no conflict of interest. 
Authors' information

1 Department of Gastroenterology and Hepatology, Municipal Hospital of Kofu, Yamanashi, Japan

2 First Department of Internal Medicine, Faculty of Medicine, University of Yamanashi, Yamanashi, Japan

\section{References}

1. Fukui H, Saito H, Ueno Y, Uto H, Obara K, Sakaida I, et al. Evidence-based clinical practice guidelines for liver cirrhosis 2015. J Gastroenterol. 2016;51(7):629-50. PubMed PMID: 27246107.

2. Shiraki M, Nishiguchi S, Saito M, Fukuzawa Y, Mizuta T, Kaibori M, et al. Nutritional status and quality of life in current patients with liver cirrhosis as assessed in 2007-2011. Hepatol Res. 2013;43(2):106-12. PubMed PMID: 23409849.

3. Nishikawa H, Yoh K, Enomoto H, Iwata Y, Kishino K, Shimono Y, et al. Factors Associated With Protein-energy Malnutrition in Chronic Liver Disease: Analysis Using Indirect Calorimetry. Medicine (Baltimore). 2016;95(2):e2442. PubMed PMID: 26765430.

4. Tajika M, Kato M, Mohri H, Miwa Y, Kato T, Ohnishi H, et al. Prognostic value of energy metabolism in patients with viral liver cirrhosis. Nutrition. 2002;18(3):229-34. PubMed PMID: 11882395.

5. Carvalho L, Parise ER. Evaluation of nutritional status of nonhospitalized patients with liver cirrhosis. Arq Gastroenterol. 2006;43(4):269-74. PubMed PMID: 17406753.

6. Mendenhall CL, Tosch T, Weesner RE, Garcia-Pont P, Goldberg SJ, Kiernan T, et al. VA cooperative study on alcoholic hepatitis. II: Prognostic significance of protein-calorie malnutrition. Am J Clin Nutr. 1986;43(2):213-8. PubMed PMID: 3080866.

7. Okabe H, Uji Y, Nagashima K, Noma A. Enzymic determination of free fatty acids in serum. Clin Chem. 1980;26(11):1540-3. PubMed PMID: 6774837.

8. Miller MD, Crotty M, Giles LC, Bannerman E, Whitehead C, Cobiac L, et al. Corrected arm muscle area: an independent predictor of long-term mortality in community-dwelling older adults? J Am Geriatr Soc. 2002;50(7):1272-7. PubMed PMID: 12133024.

9. Saito R, Ohkawa S, Ichinose S, Nishikino M, Ikegaya N, Kumagai H. Validity of mid-arm muscular area measured by anthropometry in nonobese patients with increased muscle atrophy and variation of subcutaneous fat thickness. Eur J Clin Nutr. 2010;64(8):899-904. PubMed PMID: 20502470.

10. Kanda Y. Investigation of the freely available easy-to-use software 'EZR' for medical statistics. Bone Marrow Transplant. 2013;48(3):452-8. PubMed PMID: 23208313.

11. Nakaya Y, Okita K, Suzuki K, Moriwaki H, Kato A, Miwa Y, et al. BCAA-enriched snack improves nutritional state of cirrhosis. Nutrition. 2007;23(2):113-20. PubMed PMID: 17234504.

12. Plauth $M$, Bernal W, Dasarathy S, Merli M, Plank LD, Schutz T, et al. ESPEN guideline on clinical nutrition in liver disease. Clin Nutr. 2019;38(2):485-521. PubMed PMID: 30712783.

13. McCullough AJ, Raguso C. Effect of cirrhosis on energy expenditure. Am J Clin Nutr. 1999;69(6):1066-8. PubMed PMID: 10357723.

14. Huisman EJ, Trip EJ, Siersema PD, van Hoek B, van Erpecum KJ. Protein energy malnutrition predicts complications in liver cirrhosis. Eur J Gastroenterol Hepatol. 2011;23(11):982-9. PubMed PMID: 21971339.

15. Ziegler TR. Parenteral nutrition in the critically ill patient. N Engl J Med. 2009;361(11):1088-97. PubMed PMID: 19741230. 
16. Nakaya Y, Harada N, Kakui S, Okada K, Takahashi A, Inoi J, et al. Severe catabolic state after prolonged fasting in cirrhotic patients: effect of oral branched-chain amino-acid-enriched nutrient mixture. J Gastroenterol. 2002;37(7):531-6. PubMed PMID: 12162411.

17. Nishikawa H, Enomoto H, Yoh K, Iwata Y, Hasegawa K, Nakano C, et al. Serum hyaluronic acid predicts proteinenergy malnutrition in chronic hepatitis C. Medicine (Baltimore). 2016;95(24):e3920. PubMed PMID: 27311000.

18. Terakura Y, Shiraki M, Nishimura K, Iwasa J, Nagaki M, Moriwaki H. Indirect calorimetry and anthropometry to estimate energy metabolism in patients with liver cirrhosis. J Nutr Sci Vitaminol (Tokyo). 2010;56(6):372-9. PubMed PMID: 21422706.

19. Hanai T, Shiraki M, Nishimura K, Imai K, Suetsugu A, Takai K, et al. Free fatty acid as a marker of energy malnutrition in liver cirrhosis. Hepatol Res. 2014;44(2):218-28. PubMed PMID: 23601060.

20. Izawa S, Enoki H, Hirakawa $Y$, Iwata $M$, Hasegawa J, Iguchi $A$, et al. The longitudinal change in anthropometric measurements and the association with physical function decline in Japanese community-dwelling frail elderly. $\mathrm{Br} \mathrm{J}$ Nutr. 2010;103(2):289-94. PubMed PMID: 19747412.

21. Alberino F, Gatta A, Amodio P, Merkel C, Di Pascoli L, Boffo G, et al. Nutrition and survival in patients with liver cirrhosis. Nutrition. 2001;17(6):445-50. PubMed PMID: 11399401.

22. Hayashi F, Momoki C, Yuikawa M, Simotani Y, Kawamura E, Hagihara A, et al. Nutritional status in relation to lifestyle in patients with compensated viral cirrhosis. World J Gastroenterol. 2012;18(40):5759-70. PubMed PMID: 23155318.

23. Inoue A, Kuzuya M, Cheng X. [Aging-related frailty and sarcopenia. Frailty - Sarcopenia and biomarker.]. Clin Calcium. 2018;28(9):1191-200. PubMed PMID: 30146504.

24. Joshi-Barve S, Barve SS, Amancherla K, Gobejishvili L, Hill D, Cave M, et al. Palmitic acid induces production of proinflammatory cytokine interleukin-8 from hepatocytes. Hepatology. 2007;46(3):823-30. PubMed PMID: 17680645.

25. Kawaguchi T, Taniguchi E, Itou M, Mutou M, Ibi R, Shiraishi S, et al. Supplement improves nutrition and stresses caused by examination-associated fasting in patients with liver cirrhosis. Hepatol Res. 2008;38(12):1178-85. PubMed PMID: 18631252.

26. Yamanaka-Okumura $H$, Nakamura T, Takeuchi $H$, Miyake $H$, Katayama T, Arai $H$, et al. Effect of late evening snack with rice ball on energy metabolism in liver cirrhosis. Eur J Clin Nutr. 2006;60(9):1067-72. PubMed PMID: 16508643.

27. Taniguchi E, Kawaguchi T, Sakata M, Itou M, Oriishi T, Sata M. Lipid profile is associated with the incidence of cognitive dysfunction in viral cirrhotic patients: A data-mining analysis. Hepatol Res. 2013;43(4):418-24. PubMed PMID: 22882558.

28. Merli M, Riggio O, Romiti A, Ariosto F, Mango L, Pinto G, et al. Basal energy production rate and substrate use in stable cirrhotic patients. Hepatology. 1990;12(1):106-12. PubMed PMID: 2373471.

29. Soeters MR, Sauerwein HP, Groener JE, Aerts JM, Ackermans MT, Glatz JF, et al. Gender-related differences in the metabolic response to fasting. J Clin Endocrinol Metab. 2007;92(9):3646-52. PubMed PMID: 17566089.

30. Hedrington MS, Davis SN. Sexual Dimorphism in Glucose and Lipid Metabolism during Fasting, Hypoglycemia, and Exercise. Front Endocrinol (Lausanne). 2015;6(61):61. PubMed PMID: 25964778.

31. Merli M, Riggio O, Dally L. Does malnutrition affect survival in cirrhosis? PINC (Policentrica Italiana Nutrizione Cirrosi). Hepatology. 1996;23(5):1041-6. PubMed PMID: 8621131.

32. Shiraki M, Terakura Y, Iwasa J, Shimizu M, Miwa Y, Murakami N, et al. Elevated serum tumor necrosis factor-alpha and soluble tumor necrosis factor receptors correlate with aberrant energy metabolism in liver cirrhosis. Nutrition. 2010;26(3):269-75. PubMed PMID: 19695831.

33. Peters M. Actions of cytokines on the immune response and viral interactions: an overview. Hepatology. 1996;23(4):909-16. PubMed PMID: 8666349. 
34. Al-Humadi HW, Al-Saigh R, Sahib A. The impact of low alcohol consumption on the liver and inflammatory cytokines in diabetic rats. Adv Clin Exp Med. 2019;28(3):331-7. PubMed PMID: 30170484.

35. Andus T, Bauer J, Gerok W. Effects of cytokines on the liver. Hepatology. 1991;13(2):364-75. PubMed PMID: 1995444.

36. Tilg H, Wilmer A, Vogel W, Herold M, Nolchen B, Judmaier G, et al. Serum levels of cytokines in chronic liver diseases. Gastroenterology. 1992;103(1):264-74. PubMed PMID: 1612333.

37. von Baehr V, Docke WD, Plauth M, Liebenthal C, Kupferling S, Lochs H, et al. Mechanisms of endotoxin tolerance in patients with alcoholic liver cirrhosis: role of interleukin 10, interleukin 1 receptor antagonist, and soluble tumour necrosis factor receptors as well as effector cell desensitisation. Gut. 2000;47(2):281-7. PubMed PMID: 10896923.

38. Choi KM, Han K, Park S, Chung HS, Kim NH, Yoo HJ, et al. Implication of liver enzymes on incident cardiovascular diseases and mortality: A nationwide population-based cohort study. Sci Rep. 2018;8(1):3764. PubMed PMID: 29491346.

39. Colapietro F, Aghemo A. Do gamma-glutamyltransferase levels identify HCV patients who require lifelong post-SVR follow-up? Liver Int. 2020;40(3):509-10. PubMed PMID: 32124542.

40. Guidelines for the use of parenteral and enteral nutrition in adult and pediatric patients. JPEN J Parenter Enteral Nutr. 2002;26(1 Suppl):1SA-138SA. PubMed PMID: 11841046.

41. Campillo B, Bories PN, Leluan M, Pornin B, Devanlay M, Fouet P. Short-term changes in energy metabolism after 1 month of a regular oral diet in severely malnourished cirrhotic patients. Metabolism. 1995;44(6):765-70. PubMed PMID: 7783661.

42. Miwa $Y$, Shiraki M, Kato M, Tajika M, Mohri H, Murakami N, et al. Improvement of fuel metabolism by nocturnal energy supplementation in patients with liver cirrhosis. Hepatol Res. 2000;18(3):184-9. PubMed PMID: 11058823.

43. Kato M, Moriwaki H. Metabolic disorders in patients with liver cirrhosis. Hepatol Res. 2004;30:59-62. PubMed PMID: 15607140.

\section{Tables}

Table1. Baseline characteristics of patients with chronic liver diseases. 


\begin{tabular}{|c|c|c|c|c|c|}
\hline & & All $(n=295)$ & LES- $(n=276)$ & LES $+(n=19)$ & $\begin{array}{l}\mathrm{P} \\
\text { value }\end{array}$ \\
\hline Age: years & & $72(63-80)$ & 72(63-79) & $71(65-81)$ & 0.99 \\
\hline Men: n (\%) & & $172(58 \%)$ & 158 (58\%) & $14(74 \%)$ & 0.23 \\
\hline LC: n (\%) & & $195(66 \%)$ & $176(64 \%)$ & $19(100 \%)$ & 0.001 \\
\hline $\begin{array}{l}\text { Child-Pugh } \\
\text { grade: n (\%) }\end{array}$ & $A / B / C$ & $224 / 57 / 14(76 / 19 / 5 \%)$ & $218 / 49 / 9(79 / 18 / 3 \%)$ & $6 / 8 / 5(32 / 42 / 26 \%)$ & $<0.001$ \\
\hline \multirow{5}{*}{$\begin{array}{l}\text { Comorbidities: } \\
\mathrm{n}(\%)\end{array}$} & Diabetes & $79(27 \%)$ & $76(28 \%)$ & $3(16 \%)$ & 0.42 \\
\hline & Heart disease & $35(12 \%)$ & $33(12 \%)$ & $2(11 \%)$ & 1.0 \\
\hline & $\begin{array}{l}\text { Chronic lung } \\
\text { disease }\end{array}$ & $19(6.4 \%)$ & $19(7 \%)$ & $0(0 \%)$ & 0.62 \\
\hline & $\begin{array}{l}\text { Cerebrovascular } \\
\text { disease }\end{array}$ & $26(8.8 \%)$ & $26(10 \%)$ & $0(0 \%)$ & 0.43 \\
\hline & $\begin{array}{l}\text { Chronic renal } \\
\text { disease }\end{array}$ & $30(10 \%)$ & $26(10 \%)$ & $4(21 \%)$ & 0.12 \\
\hline BMl: kg/m² & & $23(21-25)$ & $23(20-25)$ & $23(21-25)$ & 0.64 \\
\hline$\% A C: \%$ & & $92(80-99)$ & $92(80-99)$ & $84(80-97)$ & 0.67 \\
\hline $\begin{array}{l}\text { L4 } \\
\text { SFMI: } \mathrm{cm}^{2} / \mathrm{m}^{2}\end{array}$ & & $38(24-57)$ & $38(25-58)$ & $28(17-52)$ & 0.12 \\
\hline $\begin{array}{l}\text { L4 } \\
\text { VFMI: } \mathrm{cm}^{2} / \mathrm{m}^{2}\end{array}$ & & $39(24-56)$ & $39(25-58)$ & $32(22-48)$ & 0.17 \\
\hline Albumin: g/dl & & $4.0(3.5-4.3)$ & $4(3.6-4.3)$ & $2.9(2.6-3.6)$ & $<0.001$ \\
\hline $\begin{array}{l}\text { Total bilirubin: } \\
\text { g/dl }\end{array}$ & & $0.8(0.6-1.2)$ & $0.8(0.6-1.2)$ & $1.2(0.65-1.9)$ & 0.037 \\
\hline Y-GTP: U/I & & $34(21-90)$ & $33(20-87)$ & $87(32-106)$ & 0.044 \\
\hline AST:IU/I & & $28(20-42)$ & $27(20-42)$ & $36(25-51)$ & 0.12 \\
\hline ALT:IU/I & & $22(15-35)$ & $22(15-35)$ & $24(13-34)$ & 0.91 \\
\hline $\begin{array}{l}\text { Platelet: } \times 10^{3} / \\
\text { l }\end{array}$ & & 152(111-196) & 154(116-198) & $96(80-132)$ & $<0.001$ \\
\hline $\begin{array}{l}\text { Prothrombin } \\
\text { time: \% }\end{array}$ & & $85(71-95)$ & $85(72-95)$ & $64(60-83)$ & 0.003 \\
\hline $\begin{array}{l}\text { Free fatty } \\
\text { acid: } \mu \mathrm{Eq} / \mathrm{l}\end{array}$ & & $400(179-616)$ & $415(198-616)$ & $100(62-399)$ & 0.003 \\
\hline
\end{tabular}

Continuous values are expressed as median and range. LES; late evening snack, BMI; body mass index, AC; Arm circumference, SFMl; subcutaneous fat mass index, VFMI; visceral fat mass index, Y-GTP; gamma-glutamyl transpeptidase, AST; asparate aminotransferase, ALT; alanine aminotransferase.

Table2. Characteristics of patients without a LES; patients with EM versus patients without EM. 


\begin{tabular}{|c|c|c|c|c|}
\hline & & Without EM $(n=178)$ & With EM (n=98) & $\begin{array}{l}P \\
\text { value }\end{array}$ \\
\hline Age: years & & 71(61-79) & $63(66-81)$ & 0.12 \\
\hline Men: n (\%) & & $105(59 \%)$ & $53(54 \%)$ & 0.45 \\
\hline Child-Pugh grade: $\mathrm{n}(\%)$ & $\mathrm{A} / \mathrm{B} / \mathrm{C}$ & $152 / 21 / 5(85 / 12 / 3 \%)$ & $66 / 28 / 4(67 / 29 / 4 \%)$ & 0.001 \\
\hline \multirow[t]{5}{*}{ Comorbidities: n (\%) } & Diabetes & $46(26 \%)$ & $30(31 \%)$ & 0.48 \\
\hline & Heart disease & $22(12 \%)$ & $11(11 \%)$ & 0.85 \\
\hline & $\begin{array}{l}\text { Chronic lung } \\
\text { disease }\end{array}$ & $14(8 \%)$ & $5(5.1 \%)$ & 0.46 \\
\hline & $\begin{array}{l}\text { Cerebrovascular } \\
\text { disease }\end{array}$ & $21(11 \%)$ & $6(6.1 \%)$ & 0.60 \\
\hline & $\begin{array}{l}\text { Chronic renal } \\
\text { disease }\end{array}$ & $18(10 \%)$ & $8(8.2 \%)$ & 0.67 \\
\hline BMI: kg/m² & & $23(21-25)$ & 21(19-24) & 0.001 \\
\hline$\% A C: \%$ & & 99(97-104) & $84(75-90)$ & $<0.001$ \\
\hline L4 SFMI: $\mathrm{cm}^{2} / \mathrm{m}^{2}$ & & $47 \pm 27$ & $40 \pm 32$ & 0.063 \\
\hline L4 VFMI: $\mathrm{cm}^{2} / \mathrm{m}^{2}$ & & $45 \pm 25$ & $39 \pm 25$ & 0.069 \\
\hline $\begin{array}{l}\text { Radiological attenuation of } \\
\text { iliopsoas muscle: HU }\end{array}$ & & $49 \pm 12$ & $46 \pm 13$ & 0.051 \\
\hline Y-GTP: U/I & & $32(19-61)$ & $47(23-162)$ & 0.001 \\
\hline AST:IU/I & & 26(19-37) & $32(25-52)$ & $<0.001$ \\
\hline ALT:IU/I & & $20(15-30)$ & $28(17-43)$ & 0.003 \\
\hline Platelet: $\times 10^{3} / \mu \mathrm{l}$ & & $160(122-194)$ & 153(97-205) & 0.33 \\
\hline Free fatty acid: $\mu E q / l$ & & $323(168-482)$ & $753(544-940)$ & $<0.001$ \\
\hline
\end{tabular}

Continuous values are expressed as median and range. LES; late evening snack, EM; energy malnutrition, BMl; body mass index, AC; Arm circumference, SFMl; subcutaneous fat mass index, VFMl; visceral fat mass index, HU; Hounsfield Units, Y-GTP; gamma-glutamyl transpeptidase, AST; asparate aminotransferase, ALT; alanine aminotransferase.

Table3. Univariate analysis of factors linked to EM in patients with chronic liver disease without a LES. 


\begin{tabular}{|llll|}
\hline & Odds ratio & $95 \% \mathrm{Cl}$ & P value \\
\hline Age: years & 1.02 & $1.0-1.04$ & 0.073 \\
\hline Males & 0.81 & $0.49-1.3$ & 0.40 \\
\hline Child-Pugh grade B or C & 2.8 & $1.6-5.1$ & $<0.001$ \\
\hline BMl:kg/m² & 0.91 & $0.85-0.98$ & 0.010 \\
\hline Y-GTP: U/I & 1.01 & $1.0-1.01$ & $<0.001$ \\
\hline AST: IU/L & 1.02 & $1.01-1.03$ & $<0.001$ \\
\hline ALT: IU/L & 1.02 & $1.01-1.03$ & $<0.001$ \\
\hline
\end{tabular}

LES; late evening snack, EM; energy malnutrition, BMI; body mass index,Y-GTP; gamma-glutamyl transpeptidase, AST; asparate aminotransferase, ALT; alanine aminotransferase.

Table4. Univariate analysis of factors linked to EM in patients with chronic liver disease without a LES.

\begin{tabular}{|lllllll|}
\hline & \multicolumn{5}{c|}{ Males } & \multicolumn{5}{c|}{ Females } \\
\cline { 2 - 7 } & Odds ratio & $95 \% \mathrm{Cl}$ & P value & Odds ratio & $95 \% \mathrm{Cl}$ & P value \\
\hline Child-Pugh grade B or C & 2.9 & $1.4-6.2$ & $<0.001$ & 2.8 & $1.1-7.4$ & 0.031 \\
\hline BMI: kg/m 2 & 0.89 & $0 / 80-0.99$ & 0.025 & 0.93 & $0.85-1.0$ & 0.18 \\
\hline High Y-GTP: U/I & 6.5 & $3.0-14$ & $<0.001$ & 3.4 & $1.2-9.4$ & 0.020 \\
\hline High AST: IU/L & 3.3 & $1.4-7.7$ & $<0.001$ & 3.2 & $1.3-8.0$ & 0.013 \\
\hline High ALT: IU/L & 2.4 & $1.2-4.9$ & 0.016 & 3.4 & $1.5-7.5$ & 0.0027 \\
\hline
\end{tabular}

LES; late evening snack, EM; energy malnutrition,Y-GTP; gamma-glutamyl transpeptidase, AST; asparate aminotransferase, ALT; alanine aminotransferase.

Table5. Univariate and Multivariate analyses of factors linked to EM in patients with Child-Pugh A without LES.

\begin{tabular}{|lllllll|}
\hline & \multicolumn{5}{c|}{ Univariate } & \multicolumn{5}{c|}{ Multivariate } \\
\cline { 2 - 7 } & Odds ratio & $95 \% \mathrm{Cl}$ & P value & Odds ratio & $95 \% \mathrm{Cl}$ & P value \\
\hline High Y-GTP: U/I & 6.7 & $3.0-15$ & $<0.001$ & 5.1 & $2.2-12$ & $<0.001$ \\
\hline High transaminases: IU/L & 3.7 & $1.8-7.6$ & $<0.001$ & 2.7 & $1.3-5.6$ & $<0.001$ \\
\hline
\end{tabular}

LES; late evening snack, EM; energy malnutrition, Y-GTP; gamma-glutamyl transpeptidase, AST; asparate aminotransferase, ALT; alanine aminotransferase. 


\section{Figures}

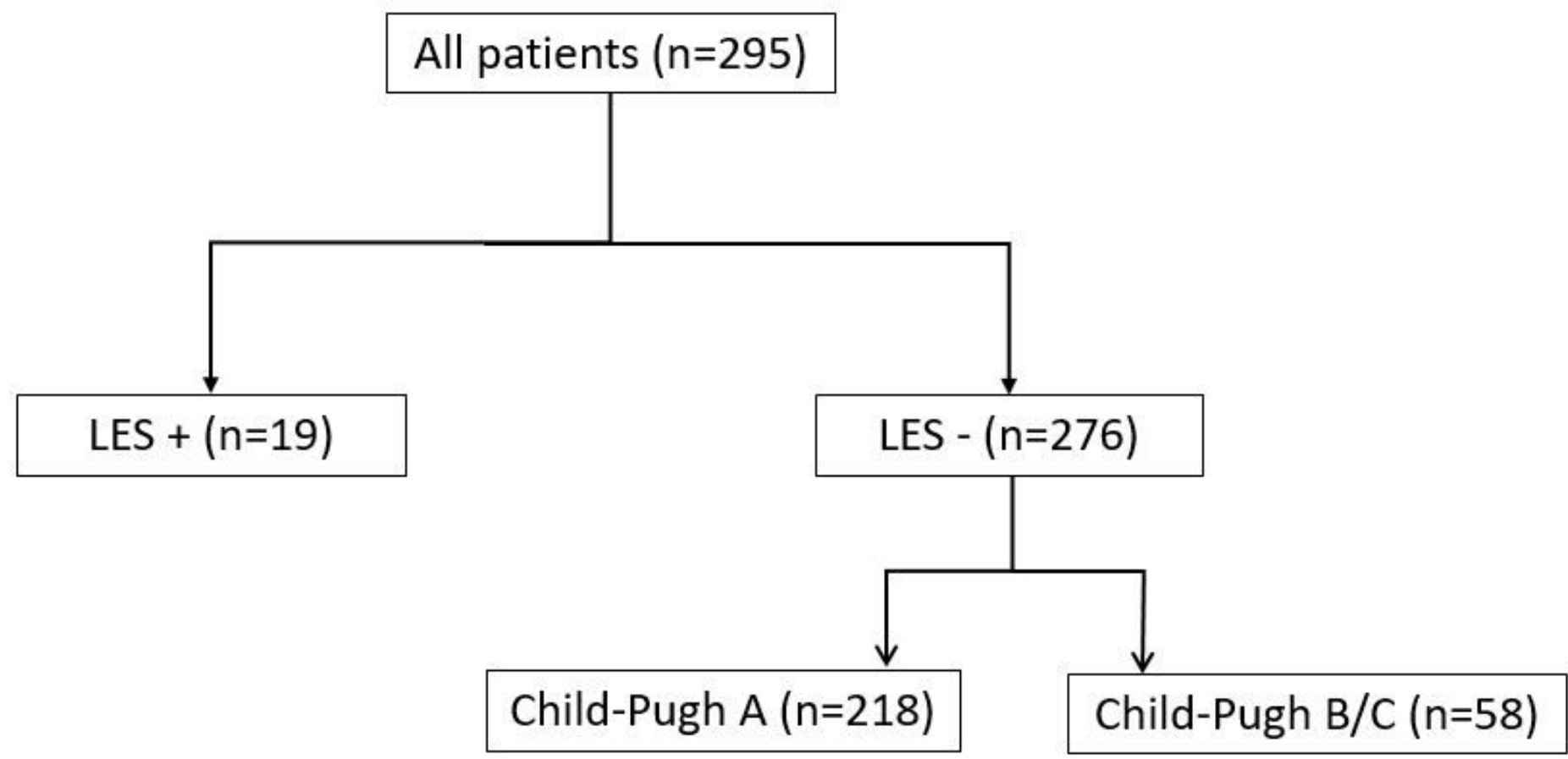

Figure 1

Patient flow in this study.



Figure 2

Overall survival; patients with EM versus patients without a EM. 


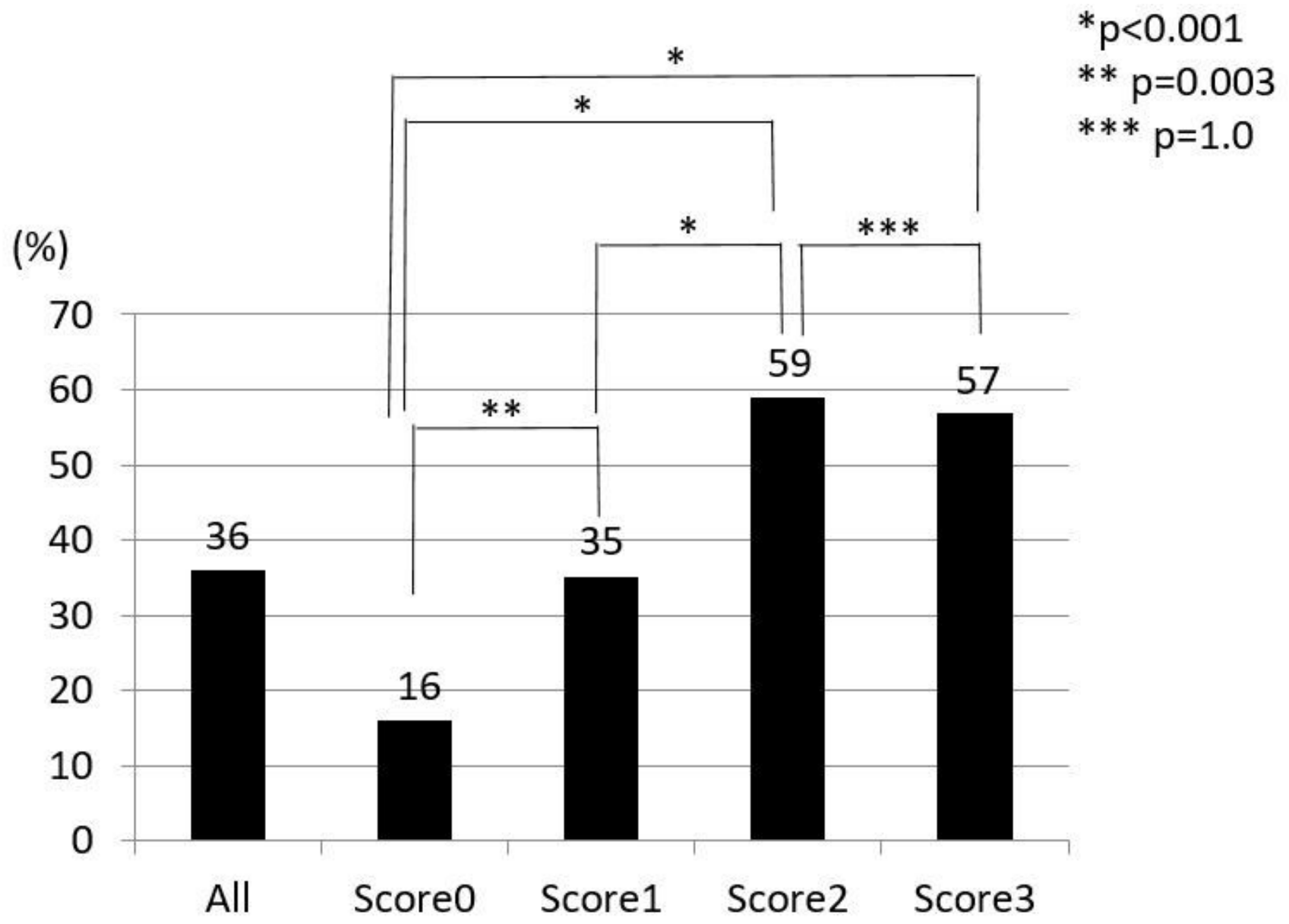

Figure 3

Frequency of EM in patients with chronic liver diseases stratified by three risk scores (Child-Pugh grade B or C, increased $\mathrm{Y}$-GTP, and increased AST or ALT). 


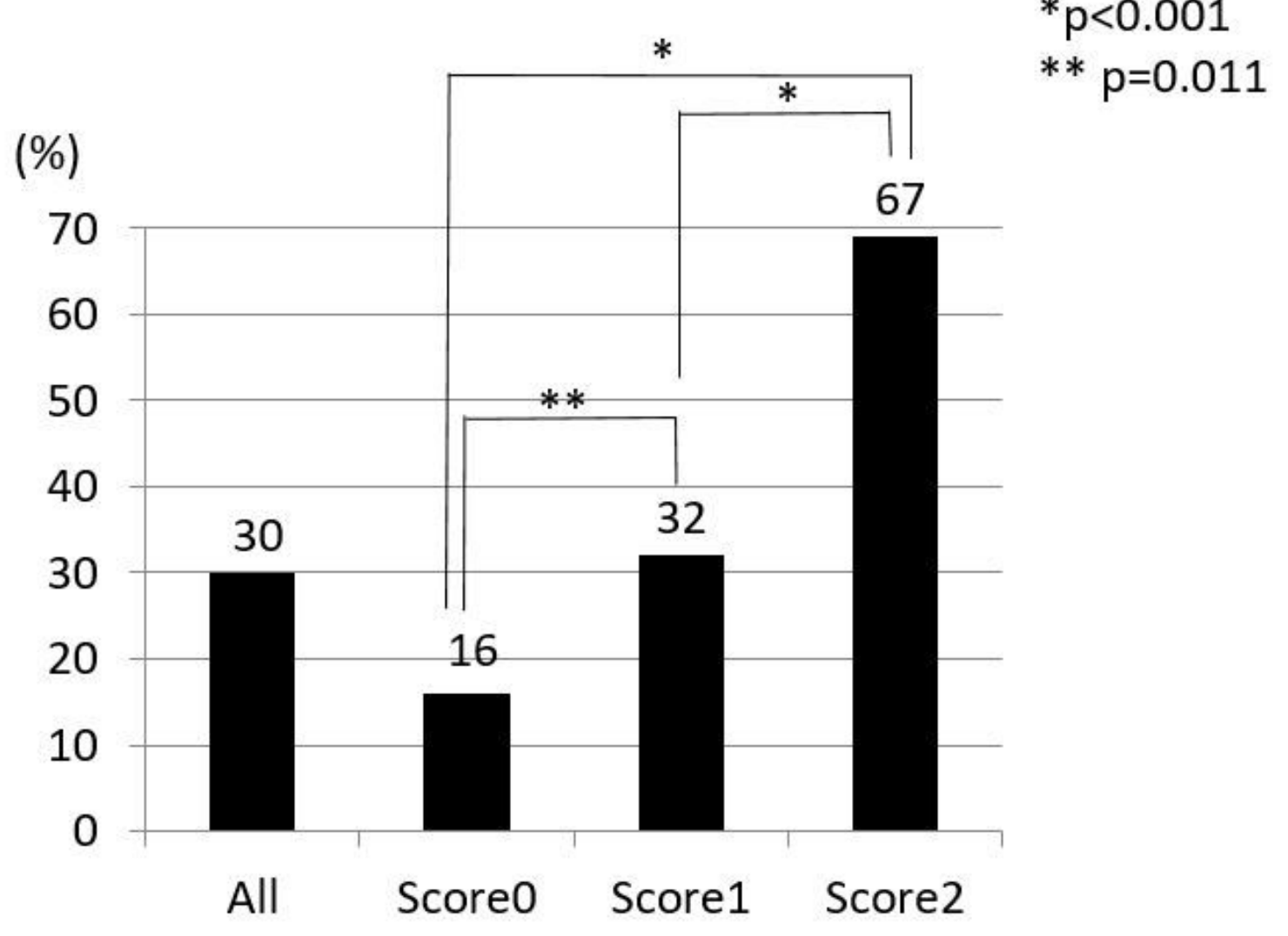

Figure 4

Frequency of EM in patients with Child-Pugh grade A stratified by two risk scores (increased $\mathrm{Y}$-GTP, and increased AST or ALT). 


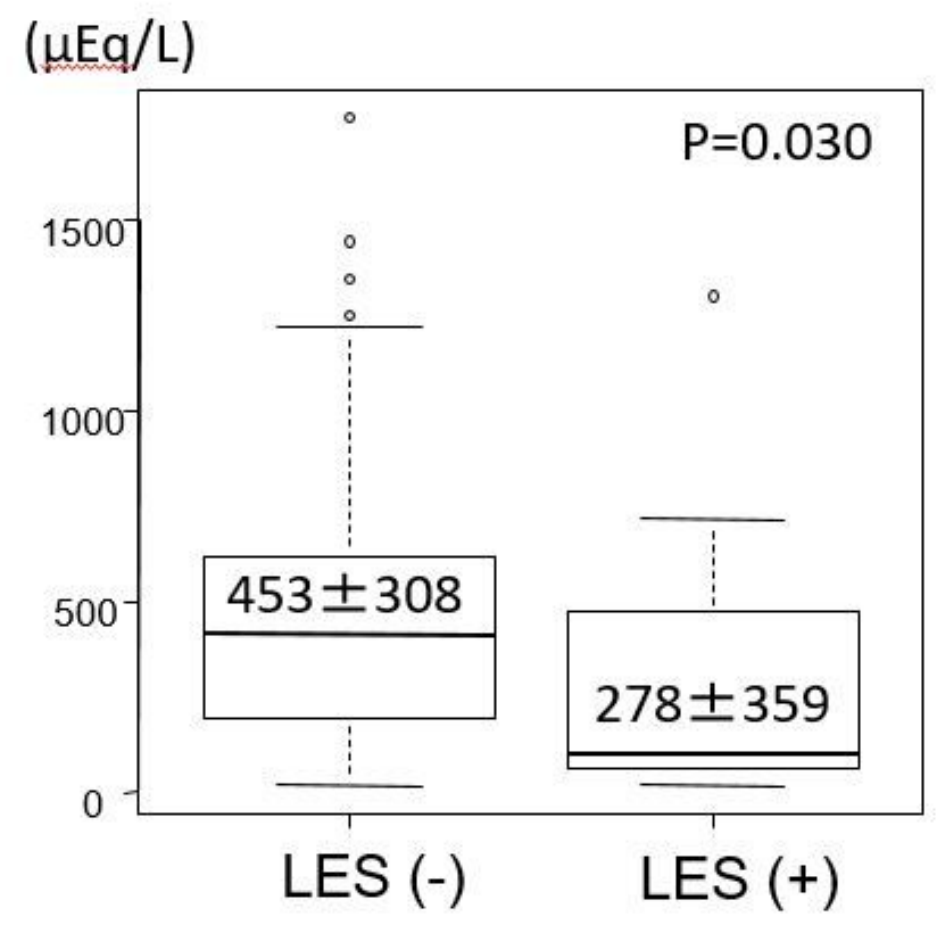

Figure 5

FFA levels between the patients with a LES and those without a LES. 